ÖĞRETMENLERDE KAS-İSKELET SISTEMI AĞRISININ PREVALANSI VE AĞRI İLE EMOSYONEL DURUM, YAȘAM KALITESİ VE VÜCUT FARKINDALIĞI ARASINDAKİ ILISSKKI ${ }^{1}$

\title{
THE PREVALENCE OF MUSCULOSKELETAL PAIN IN TEACHERS AND THE RELATIONSHIP AMONG PAIN AND EMOTIONAL STATUS, QUALITY OF LIFE AND BODY AWARENESS
}

\author{
Mehmet GÖĞREMIŞS', Mehtap OMAÇ SÖNMEZ ${ }^{2}$ \\ ${ }^{1-2}$ Kahramanmaraş Sütçü İmam Üniversitesi, KahramanmaraşS Sağlık Yüksekokulu, \\ Kahramanmaraş / Türkiye
}

ORCID ID: 0000-0001-6420-2267', 0000-0001-6975-0262 ${ }^{2}$

Öz: Amac: Bu çalışmanın amacı öğretmenlerde kas iskelet sistemi ağrısı (KiSA) prevalansının saptanması, ağrının emosyonel durum, yaşam kalitesi ve vücut farkındalı̆ı̆ üzerine olan etkilerinin belirlenmesidir. Yöntem: Kesitsel olarak yapılan bu çalışmaya devlet okullarında çalışan 555 öğretmen dâhil edilmiștir. Öğretmenlerin yașam kalitesini değerlendirmek amacıyla SF-36 yaşam kalitesi anketi, emosyonel durumu saptamak amacıyla Beck Depresyon Ölçeği (BDÖ), vücut farkındalığını değerlendirmek amacıyla Vücut Farkındalık Anketi (VFA) ve ağrı şiddetini ölçmek amacıyla Görsel Analog Skala (GAS) kullanıldı. Bulgular: Öğretmenlerin (n:555) 280'i kadın, 275'i erkek, yaş ortalamaları 38.61 \pm 9.37 yıldır. Araştırmaya dahil edilen 413 öğretmen kas iskelet sisteminde ağrı olduğunu bildirmiștir. En çok ağriyan bölgeler bel (\%46.9), boyun (\%39.6), surt (\%36.2) ve omuz (\%32.5) olarak saptandı. Kas iskelet sistemi ağrisı olan öğretmenlerin BDÖ skoru yüksek, SF-36 skoru düşük bulundu $(\mathrm{p}<0.005)$. Kas iskelet sistemi ağrıs olan ve olmayan öğretmenlerin VFA skorları arasında fark saptanmadı $(\mathrm{p}=0.512)$. Sonuç: Öğretmenlerde KISAA prevalansının yüksek olduğu, buna bağlı olarak KiSA olan öğretmenlerde yaşam kalitesinde azalma ve depresyona yatkınlık saptandı.

Anahtar Kelimeler: Kas İskelet Sistemi Ağrısı, Vücut Farkındalı̆ı̆ı, Depresyon, Yaşam Kalitesi, Öğretmen
Abstract: Aim: The aim of this study was to determine the prevalence of musculoskeletal system pain (MSP), the effects of pain on emotional status, quality of life and body awareness in the intended teachers. Method: This cross-sectional study included 555 teachers working in public schools. The SF-36 quality of life questionnaire was used to assess the quality of life of the teachers, the Beck Depression Inventory (BDI) to assess the emotional state, the Body Awareness Questionnaire (BDQ) to assess body awareness and the Visual Analogue Scale (VAS) to measure pain severity. Results: $280(\mathrm{n}=555)$ teachers were female and 275 were male, mean of age was $38.61 \pm 9.37$ years. Included in this study, 413 teachers reported that they had pain in the musculoskeletal system. The most common areas were waist $(46.9 \%)$, neck $(39.6 \%)$, back $(36.2 \%)$ and shoulder $(32.5 \%)$. Teachers with pain in the musculoskeletal system had a high BDI score and a low score of SF-36 $(\mathrm{p}<0.005)$. There was no difference between body awareness questionnaire scores of teachers with and without pain in the musculoskeletal system ( $\mathrm{p}=0.512$ ). Conclusion: The prevalence of pain in the MSP was high in the teachers and accordingly, the teachers who had the MSP had a decrease in quality of life and a predisposition to depression.

Key Words: Musculoskeletal System Pain, Body Awareness, Depression, Life Quality, Teacher

Doi: $10.17363 / S S T B .2018 .2 .2$

(1) Sorumlu Yazar: Mehmet GÖĞREMiş, Kahramanmaraş Sütçü İmam Üniversitesi, Kahramanmaraş Sağllk Yüksekokulu, Kahramanmaraş/Türkiye, fzzt_mehmetgogremis@hotmail.com, Geliş Tarihi/Received: 28.02.2018, Kabul Tarihi / Accepted: 30.06.2018, Makalenin Türü: Type of article (Arașttrma - Uygulama / Research -Application) Çıkar Çatı̧ması / Conflict of Interest: Yok / None Etik Kurul Raporu/ Ethics Committee: Yes "Kahramanmaraş Sütçï İmam Üniversitesi, Tip Fakültesi, Klinik Araştrrmalar Etik Kurulu, Tarih: 01.03.2017, Sayı: 2017/03-01” 
International Refereed Academic Journal of Sports, Health and Medical Sciences April - May - June Issue: 27 Spring Summer Year: 2018

Uluslararası Hakemli Akademik Spor Sağlık ve Tıp Bilimleri Dergisi

Nisan - Mayıs - Haziran Sayı: 27 İlkbahar Yaz Dönemi Yıl: 2018 ID:381 K:476

ISSN Print: 2146-8508 Online 2147-1711

(ISO 18001-OH-0090-13001706 / ISO 14001-EM-0090-13001706 / ISO 9001-QM-0090-13001706 / ISO 10002-CM-0090-13001706) (TRADEMARK)

(2015/04315- 2015-GE-18972)

\section{Gİiș}

Kas iskelet sistemi ağrıları (KİSA), çalışan nüfusta en sık rastlanan, yaşam kalitesi üzerine önemli derecede etkisi olan, ekonomik olarak büyük bir yük oluşturan önemli sağ11k problemlerinden birisidir (Samad et al., 2010: 634-639; Correa L.A et al., 2018: 1-9). Kas iskelet sistemi hastalıkları kasları, ligamentleri, tendonları, sinirleri kemikleri ve eklemleri etkileyen inflamatuvar ve dejeneratif durumları içermektedir (Allsop\&Ackland, 2010: 61-78; Atlas et al., 2007:34-40). Bu duruma katkıda bulunan faktörler ise yorucu ve tekrarlayıcı aktiviteler ve yoğun iş yükü gibi işyeri faaliyetleridir (Smendley et al., 1995: 160-163). Yaş, cinsiyet, sigara alışkanlığı gibi demografik özelliklerin de bu duruma sebep olabilecek değişkenler olduğu bilinmektedir (Lee et al, 2017: 198-204).

Bazı meslek grubu çalışanları mesleki özelliklerden dolayı kas iskelet sistemi hastalıklarına daha fazla maruz kalırlar (Gasparini et al., 2005: 99-189). Öğretmenler bu grupta yer alırlar. Bazen öğretmenlik öğretmenlerin fiziksel, kognitif ve duygusal kapasitelerini öğretim amaçlarına ulaşmak için daha fazla çaba harcadıkları elverişsiz koşullar altında gerçekleşir (Cardoso et al.,2009:1-10). Eğer iyileşme için yeterli zaman yoksa çalışanların sağlık durumlarından kaynaklanan işten izin alma seviyesinde artış meydana gelir ve bunun sonucunda fiziksel sağlık, ruhsal sağlık ve performans etkilendiğinden eğitim işi zorlaşır (Gasparini et al., 2005: 99-189; Reis et al., 2006: 53-229).

Öğretmenlerde kas iskelet sistemi ağr1lar1nın prevalansı ile ilgili birçok uluslar arası çalışma bildirilmiştir (Chang\&Chan, 2010: 23-29; Darmawan et al., 1995: 121-124). Genel olarak öğretmenlerde kas iskelet sistemi rahatsızlıkları diğer meslek gruplarına göre oldukça fazladır (Cardoso et al., 2009: 1-10). Kas iskelet sistemi rahatsızlıkları prevalans1 Suudi Arabistan' da yapılan bir çalışmada \%79.1 (Darwish\&A1-Zuhair, 2013: 1-7), Brezilya da yapılan bir çalışmada \%55 (Cardoso et al., 2009: 1-10), ülkemizde yapılan farklı çalışmalarda \%59.4 (Durmus \&İlhanlı, 2012: 5-12) ve \%77 (Karakaya et al., 2015: 344350) olarak bildirilmiştir.

\section{AMAÇ}

Bu çalışmada öğretmenlerdeki kas iskelet sistemi ağrı prevalansının saptanması, ağrının depresif semptomlar, yaşam kalitesi ve vücut farkındalığı üzerine olan etkilerinin ortaya konması amaçlanmıştır.

\section{KAPSAM}

Çalışmaya Kahramanmaraş il merkezinde bulunan ilköğretim, ortaokul ve lise düzeylerindeki devlet okullarında aktif olarak çalışan, en az 2 yıllık mesleki deneyimi olan ve kas iskelet sistemi ile ilgili herhangi bir cerrahi 


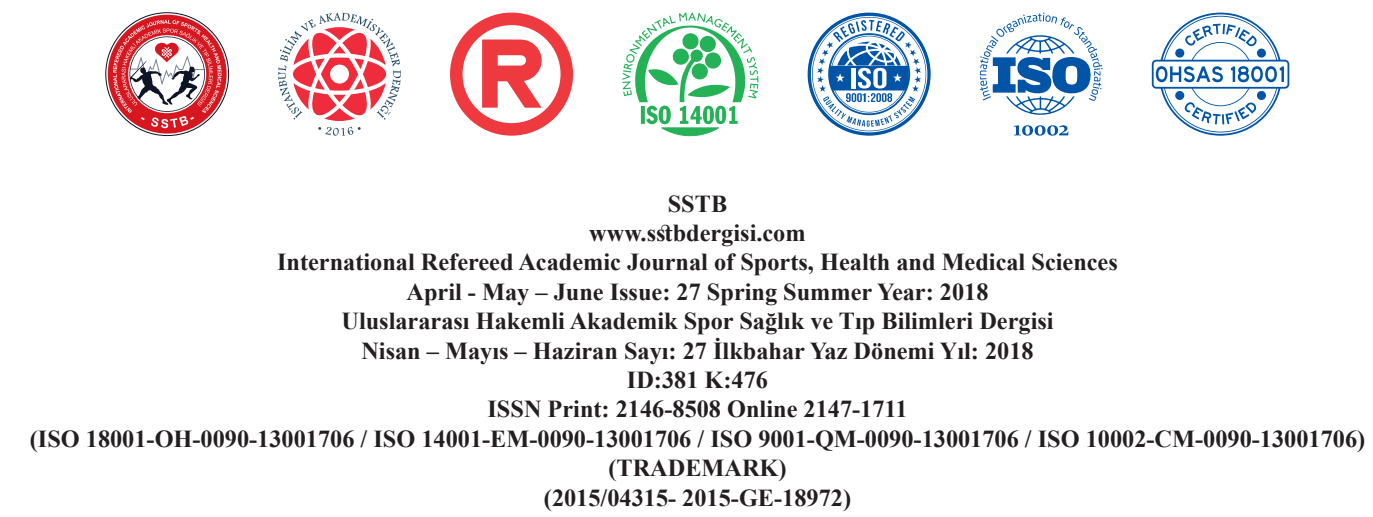

öyküsü olmayan 22-63 yaş aralığındaki 555 öğretmen dahil edilmiştir.

\section{ARAŞTIRMANIN YÖNTEMI}

Örneklem büyüklüğünün belirlenmesinde Kahramanmaraş il merkezinde görev yapan 7352 öğretmen dikkate alındı. Örneklem büyüklüğü $\alpha: 0.05$ hata düzeyi ve 0.80 testin gücü d:0.05 etki büyüklüğü ve $\% 95$ güven aralığı ile 555 öğretmen olarak tespit edildi. Katılımciların tümü yapılacak anketler hakkında aydınlatıldı ve aydınlatılmış onam formu imzalatıldı. Katılımciların bilgileri yüz yüze anket yöntemi kullanılarak alındı. Katılımcıların demografik verileri oluşturulmuş form ile kaydedildi. Veri toplama formunda aşağıdaki anket ve ölçekler kullanılmıştır.

Beck Depresyon Öıçeği (BDÖ): Emosyonel durumu değerlendirmek amacıyla kullanılan bu ölçek 0 ile 3 arası puanlanan ve her biri 4 maddeden oluşan toplam 21 sorudan oluşur. $\mathrm{Bu}$ testten alınabilecek en yüksek puan $63^{\prime}$ tür ve yüksek puan artmış depresif semptomları ifade eder (Hisli, 1998: 118-122).

Görsel Ağrı Skalası (GAS): Ağrı şiddetinin ölçülmesi amacıyla kullanılan bu skalada kişiden $100 \mathrm{~mm}$ yatay çizgi üzerinde ağrı şiddetini işaretlemesi istenir ( $0 \mathrm{~mm}$ ağrım yok, 100 $\mathrm{mm}$ dayanılmaz ağrım var anlamına gelir). Değerlendirmede $0 \mathrm{~mm}$ "ağr yok" $0.1 \mathrm{~mm}$ ve üzeri "ağrı var" olarak kabul edilmiştir. Bu skala ağrı şiddetini ölçmede geçerli, tutarlı ve tekrarlanabilir özelliktedir (Waterfield \&Sim, 1996: 94-97; Munoz et al., 2004: 43-48).

SF-36 Yaşam Kalitesi Anketi: Yaşam kalitesinin değerlendirilmesinde yaygın olarak kullanılan bu anket fiziksel fonksiyon (FF), sosyal fonksiyon (SF), fiziksel rol kisitlil1ğ1 (FRK), emosyonel rol kisttlllığı (ERK), mental sağlık (MS), enerji-bitkinlik düzeyi (EBD), ağrı (A) ve genel sağlık durumu (GSD) gibi 8 boyutu ölçmeyi sağlayan 36 sorudan oluşur. Puanlama her bir boyut için 0 (en kötü), 100 (en iyi) arasında değerlendirilir ve yüksek puan daha iyi yaşam kalitesini gösterir (Pınar, 2005: 259-264).

Vücut Farkındalık Anketi (VFA): Normal ya da normal olmayan vücut süreçlerine duyarlılı̆̆ı ölçmek amaciyla Shields ve ark. tarafından geliştirilen bu test, vücut süreçlerini tahmin etme, vücut tepkilerini tahmin etme, uyku-uyanıklık döngüsü ve hastalık başlangıcını tahmin etme gibi dört alt gruptan oluşur. Toplam 18 ifadeden oluşan bu testte katılımcıdan her bir ifade için bir ile yedi arasında puanlama yapması istenir. Değerlendirme toplan skor üzerinden yapılır ve yüksek puan vücut süreçlerine duyarlıllğın daha iyi olduğunu gösterir (Shield et al., 1989: 802-815).

Vücut Farkındalık Anketinin Türkçe versiyonu geçerlik ve güvenirlik çalışması yapılmamıştır. Anket ön denemesi araştırma kapsamına alınmayan 30 kişilik bir öğretmen 
International Refereed Academic Journal of Sports, Health and Medical Sciences April - May - June Issue: 27 Spring Summer Year: 2018

Uluslararası Hakemli Akademik Spor Sağlık ve Tıp Bilimleri Dergisi

Nisan - Mayıs - Haziran Sayı: 27 İlkbahar Yaz Dönemi Yıl: 2018 ID:381 K:476

ISSN Print: 2146-8508 Online 2147-1711

(ISO 18001-OH-0090-13001706 / ISO 14001-EM-0090-13001706 / ISO 9001-QM-0090-13001706 / ISO 10002-CM-0090-13001706) (TRADEMARK)

grubunda yapıldı ve anket Cronbach alpha düzeyi 0.88 olarak bulundu. Türkçe versiyonu anket soruları (18 soru) (Erden A. ve diğ., 2013: 145-150) hiçbir değişiklik yapılmasına ihtiyaç duyulmadan örneklem grubunda kullanildi.

Fiziksel Aktivite: Günde en az 30 dakika hafif veya orta şiddette yapılan aktiviteleri içermektedir (Türkiye Fiziksel Aktivite Rehberi, 2014). Günde 30 dakikanın altında veya hiç fiziksel aktivite yapmayanlar "Hiç", günde en az 30 dakika fiziksel aktivite yapanlar " $\geq 1 "$ olarak değerlendirildi.

Veri toplama formu aracılığıyla öğretmenlere KİSA varlığı soruldu. Ağrısı olanlarda ağrı şiddeti GAS, ağrı bölgesi vücut diyagramı ile belirlendi. Tüm öğretmenlerin emosyonel durum BDÖ, vücut farkındalık düzeyi VFA ve yaşam kalitesi SF-36 yaşam kalitesi anketi ile değerlendirildi.

Veriler Statistical Package for the Social Sciences (SPSS) versiyon 22.0 for Windows programı kullanılarak analiz edildi. Çalışmaya \%90 güç ile 555 öğretmen dahil edildi. $\mathrm{P}$ değeri 0,05 'in altında anlamlı olarak kabul edildi. Ölçülebilen veriler ortalama, standart sapma, kesikli veriler ise sıklık olarak sunuldu. Veri analizinde ağrı durumu ile bağımsız değişkenler (cinsiyet, medeni hal, dominant ekstremite, alkol kullanımı v.b) Ki-kare analizi yapılarak karşılaştırıldı. Sürekli değişkenler (Yaş, ağırlık, boy, BKİ, mesleki deneyim, haftalık çalışma süreleri) bağımsız gruplarda t testi kullanılarak karşılaștırıldı ve kullanılan ölçek ve anket ortalamaları Pearson Korelasyon analizi ile değerlendirildi.

\section{ARAŞTIRMANININ KISITLARI}

Literatürde öğretmenlerin vücut farkındalık durumu ile ilgili yapılan herhangi bir çalışmaya rastlanmamasından dolayı makalenin tartışma kısmında kıyaslama yapılamaması bu çalışmanın en önemli kısıtlılığıdır.

\section{BULGULAR}

Araştırmaya katılan öğretmenlerin kas iskelet sistemi ağrı durumları ile sosyo-demografik özellikleri karşılaştırılması tablo 1' de gösterilmiştir. 
International Refereed Academic Journal of Sports, Health and Medical Sciences April - May - June Issue: 27 Spring Summer Year: 2018

Uluslararası Hakemli Akademik Spor Sağlık ve Tıp Bilimleri Dergisi Nisan - Mayıs - Haziran Sayı: 27 İlkbahar Yaz Dönemi Yıı: 2018 ID:381 K:476

ISSN Print: 2146-8508 Online 2147-1711

(ISO 18001-OH-0090-13001706 / ISO 14001-EM-0090-13001706 / ISO 9001-QM-0090-13001706 / ISO 10002-CM-0090-13001706) (TRADEMARK)

(2015/04315- 2015-GE-18972)

Tablo 1. Öğretmenlerin Sosyo-Demografik Özellikleri ile Ağrı Durumlarının Karşılaştırılması

\begin{tabular}{|c|c|c|c|c|c|c|c|}
\hline \multirow[t]{3}{*}{ Sosyo-Demografik Özellikler } & \multirow{2}{*}{\multicolumn{2}{|c|}{ Toplam }} & \multicolumn{4}{|c|}{ Ağrı Durumu } & \multirow{3}{*}{$\begin{array}{l}\mathrm{X}^{2^{*}} \\
/ \mathrm{p}\end{array}$} \\
\hline & & & \multirow{2}{*}{$\frac{\text { Var }}{n}$} & & \multicolumn{2}{|l|}{ Yok } & \\
\hline & $\mathrm{n}$ & $\%$ & & $\%$ & & $\%$ & \\
\hline \multicolumn{8}{|l|}{ Cinsiyet } \\
\hline Kadin & 280 & 50.5 & 224 & 54.2 & 56 & 39.4 & \multirow{2}{*}{$\begin{array}{l}9.260 \\
/ \mathbf{0 . 0 0 2}\end{array}$} \\
\hline Erkek & 275 & 49.5 & 189 & 45.8 & 86 & 60.6 & \\
\hline \multicolumn{8}{|l|}{ Medeni Hal } \\
\hline Evli & 429 & 77.3 & 326 & 78.9 & 103 & 72.5 & \multirow{3}{*}{$\begin{array}{c}3.994 \\
10136\end{array}$} \\
\hline Bekar & 118 & 21.3 & 80 & 19.4 & 38 & 26.8 & \\
\hline Boşanmış & 8 & 1.4 & 7 & 1.7 & 1 & 0.7 & \\
\hline \multicolumn{8}{|l|}{ Dominant Ekstremite } \\
\hline Sağ & 483 & 87.0 & 360 & 87.2 & 123 & 86.6 & \multirow{2}{*}{$\begin{array}{l}0.028 \\
/ 0.484\end{array}$} \\
\hline Sol & 72 & 13.0 & 53 & 12.8 & 19 & 13.4 & \\
\hline \multicolumn{8}{|l|}{ Alkol Kullanımı } \\
\hline Evet & 17 & 3.1 & 11 & 2.7 & 6 & 4.2 & \multirow{2}{*}{$\begin{array}{l}0.868 \\
/ 0.250\end{array}$} \\
\hline Hayır & 538 & 96.9 & 402 & 97.3 & 136 & 95.8 & \\
\hline \multicolumn{8}{|l|}{ Sigara Kullanımı } \\
\hline Evet & 138 & 24.9 & 109 & 26.4 & 29 & 20.4 & \multirow{2}{*}{$\begin{array}{l}2.016 \\
/ 0.094\end{array}$} \\
\hline Hayır & 417 & 75.1 & 304 & 73.6 & 113 & 79.6 & \\
\hline \multicolumn{8}{|l|}{ Çalışılan Okul Düzeyi } \\
\hline İlkokul & 233 & 42.0 & 184 & 44.6 & 49 & 34.5 & \multirow{3}{*}{$\begin{array}{l}4.492 \\
/ 0.106\end{array}$} \\
\hline Ortaokul & 172 & 31.0 & 121 & 29.3 & 51 & 35.9 & \\
\hline Lise & 150 & 27.0 & 108 & 26.2 & 42 & 29.6 & \\
\hline \multicolumn{8}{|l|}{ Fiziksel aktivite kez/ hafta } \\
\hline Hiç & 218 & 39.3 & 169 & 40.9 & 49 & 34.5 & \multirow{2}{*}{$\begin{array}{l}1.822 \\
/ 0.105\end{array}$} \\
\hline$\geq 1$ & 337 & 60.7 & 244 & 59.1 & 93 & 65.5 & \\
\hline
\end{tabular}


International Refereed Academic Journal of Sports, Health and Medical Sciences April - May - June Issue: 27 Spring Summer Year: 2018

Uluslararası Hakemli Akademik Spor Sağlık ve Tıp Bilimleri Dergisi

Nisan - Mayıs - Haziran Sayı: 27 İlkbahar Yaz Dönemi Yıl: 2018 ID:381 K:476

ISSN Print: 2146-8508 Online 2147-1711

(ISO 18001-OH-0090-13001706 / ISO 14001-EM-0090-13001706 / ISO 9001-QM-0090-13001706 / ISO 10002-CM-0090-13001706) (TRADEMARK)

\section{*Ki-kare testi, $\mathbf{p}<0.05, \%$ Kolon Yüzdesi}

Katılımcıların 280'i kadın, 275'i erkekti. Katılımcıların 218'i hiç fiziksel aktivite yapmadıklarını bildirmişlerdir (Tablo 1). KİSA olan öğretmenlerin 224'ü (\%54.2) kadın, 189’u (\%45.8) erkekti. Cinsiyetler arasında KİSA prevalansı arasındaki fark anlamlı bulundu (Tablo 1). Araştırmaya dahil edilen kadın öğretmenlerin yaş ortalamaları $35.6 \pm 8.5$, erkek öğretmenlerin yaş ortalamaları 41.6 \pm 9.2 ' dir. Kadın öğretmenler \%32.5' inin 30 yaş ve al- tında olduğu, erkek öğretmenlerin ise \%51.3' ünün 40 yaş ve üzeri olduğu belirlenmiştir. BKİ göre erkek öğretmenlerin kadın öğretmenlere göre fazla kilolu (\%57.8) ve obez (\%14.5) olduğu, deneyim sürelerinin daha fazla olduğu belirlenmiştir.

KİSA durumuna göre öğretmenlerin yaş, ağırlık, boy, BKİ, mesleki deneyim ve haftalık toplam çalışma süreleri ortalamaları karş1laştırılmış ve tablo 2' de sunulmuştur.

Tablo 2. KİSA Durumuna Göre Öğretmenlerin Bazı Özellik Ortalamalarının Karşılaştırılması

\begin{tabular}{lllll} 
& \multicolumn{3}{c}{ Ağrı Durumu } & \multirow{2}{*}{ t/ $\mathrm{p}^{*}$} \\
\cline { 2 - 4 } Özellikler & $\begin{array}{l}\text { Toplam } \\
(\mathrm{n}: 555)\end{array}$ & $\begin{array}{l}\text { Var } \\
(\mathrm{n}: 413)\end{array}$ & $\begin{array}{l}\text { Yok } \\
(\mathrm{n}: 142)\end{array}$ & \\
\cline { 2 - 5 } & Ort. $\pm \mathrm{SS}$ & Ort. \pm SS & Ort. \pm SS & $-0.345 / 0.730$ \\
\hline Yaş (yıl) & $38.61 \pm 9.37$ & $38.53 \pm 9.20$ & $38.85 \pm 9.87$ & $-0.984 / 0.326$ \\
\hline Ağırlık (kg) & $72.64 \pm 13.52$ & $72.31 \pm 13.54$ & $73.60 \pm 13.46$ & $-1.080 / 0.281$ \\
\hline Boy (m) & $1.68 \pm 0.08$ & $1.68 \pm 0.08$ & $1.69 \pm 0.07$ & $-0.412 / 0.681$ \\
\hline BKİ & $25.36 \pm 3.69$ & $25.32 \pm 3.77$ & $25.47 \pm 3.48$ & $-0.444 / 0.657$ \\
\hline Mesleki deneyim (yıl) & $14.93 \pm 9.35$ & $14.83 \pm 9.16$ & $15.23 \pm 9.90$ & $-1.080 / 0.280$
\end{tabular}

\section{*Bağımsız gruplarda $\mathbf{T}$ testi $\mathbf{p}<\mathbf{0 . 0 5}$}

Öğretmenlerin yaş ortalaması $38.61 \pm 9.37$ yıl, BKİ ortalama değeri $25.21 \pm 3.69$, ortalama mesleki deneyim süresi $14.93 \pm 9.35$ y1l (2-41 y1l) ve ortalama haftalık çalışma süresi 30.07 \pm 8.4 saat (2-56 saat) olarak bulundu.
KİSA olan öğretmenlerle olmayanlar karş1laştırıldığında yaş, BKİ, mesleki deneyim süresi ve haftalık çalışma süreleri açısından anlamlı bir farklılık bulunamadı (Tablo 2).

Ağrı bölgelerinin cinsiyete göre karşılaştırılması Tablo 3' te sunulmuştur. 
SSTB

www.sstbdergisi.com

International Refereed Academic Journal of Sports, Health and Medical Sciences April - May - June Issue: 27 Spring Summer Year: 2018

Uluslararası Hakemli Akademik Spor Sağlık ve Tıp Bilimleri Dergisi

Nisan - Mayıs - Haziran Sayı: 27 İlkbahar Yaz Dönemi Yıl: 2018 ID:381 K:476

ISSN Print: 2146-8508 Online 2147-1711

(ISO 18001-OH-0090-13001706 / ISO 14001-EM-0090-13001706 / ISO 9001-QM-0090-13001706 / ISO 10002-CM-0090-13001706) (TRADEMARK)

(2015/04315- 2015-GE-18972)

Tablo 3. Ağrı Bölgelerinin Cinsiyete Göre Karşılaştırılması

\begin{tabular}{|c|c|c|c|c|c|}
\hline & \multicolumn{2}{|c|}{ Kadın } & & Erkek & \multirow[t]{2}{*}{$\mathbf{X}^{2} / \mathbf{p}^{*}$} \\
\hline & & & & & \\
\hline Boyun & 144 & 51.4 & 80 & 29.1 & $28.760 / \mathbf{0 . 0 0 0}$ \\
\hline Omuz & 117 & 41.8 & 63 & 22.9 & $22.559 / \mathbf{0 . 0 0 0}$ \\
\hline Dirsek & 35 & 12.5 & 26 & 9.5 & $2.0012 / 0.100$ \\
\hline $\mathrm{El}$ & 57 & 20.4 & 27 & 9.8 & $11.997 / \mathbf{0 . 0 0 0}$ \\
\hline Sirt & 121 & 43.2 & 81 & 29.5 & $11.347 / \mathbf{0 . 0 0 1}$ \\
\hline Bel & 141 & 50.4 & 118 & 42.9 & $3.092 / \mathbf{0 . 0 4 2}$ \\
\hline Kalça & 56 & 20.0 & 36 & 13.1 & 4.789/0.019 \\
\hline Diz & 88 & 31.4 & 86 & 31.3 & $0.002 / 0.521$ \\
\hline Ayak & 97 & 59.6 & 63 & 40.4 & $9.310 / \mathbf{0 . 0 0 2}$ \\
\hline
\end{tabular}

* Ki-kare testi, p<0.05, \% Kolon Yüzdesi

Erkek öğretmenler arasında en fazla görülen ağrı bölgesi bel, kadın öğretmenlerde ise boyun bölgesiydi (Tablo 3 ).
Ağrı bölgesi GAS skoru ortalamalarının cinsiyete göre karşılaştırılması Tablo 4' de gösterilmiştir. 
International Refereed Academic Journal of Sports, Health and Medical Sciences April - May - June Issue: 27 Spring Summer Year: 2018

Uluslararası Hakemli Akademik Spor Sağlık ve Tıp Bilimleri Dergisi

Nisan - Mayıs - Haziran Sayı: 27 İlkbahar Yaz Dönemi Yıl: 2018 ID:381 K:476

ISSN Print: 2146-8508 Online 2147-1711

(ISO 18001-OH-0090-13001706 / ISO 14001-EM-0090-13001706 / ISO 9001-QM-0090-13001706 / ISO 10002-CM-0090-13001706) (TRADEMARK)

(2015/04315- 2015-GE-18972)

Tablo 4. Cinsiyete Göre GAS Ortalamalarının ve Ağrı Bölgelerinin Karşılaştırılması

\begin{tabular}{|c|c|c|c|c|c|c|}
\hline \multirow{3}{*}{$\begin{array}{l}\text { Ağrı Böl- } \\
\text { gesi }\end{array}$} & & & & \multicolumn{2}{|c|}{ Görsel Analog Skalası (GAS) } & \multirow{3}{*}{$\mathrm{t} / \mathrm{p}^{*}$} \\
\hline & & & & \multirow{2}{*}{$\begin{array}{l}\text { Kadın } \\
\text { Ort. } \pm \text { S.S }\end{array}$} & \multirow{2}{*}{$\begin{array}{l}\text { Erkek } \\
\text { Ort. } \pm \text { S.S }\end{array}$} & \\
\hline & n $(\%)$ & Ort. \pm S.S & Min-Max & & & \\
\hline Boyun & $220(39.6)$ & $4.66 \pm 2.48$ & $0.2-10.0$ & $4.99 \pm 2.43$ & $4.07 \pm 2.46$ & $2.663 / \mathbf{0 . 0 0 8}$ \\
\hline Omuz & 182(32.5) & $4.94 \pm 2.34$ & $0.8-10.0$ & $5.18 \pm 2.28$ & $4.47 \pm 2.39$ & $1.931 / 0.055$ \\
\hline Dirsek & $61(11.0)$ & $3.38 \pm 2.52$ & $0.7-10.0$ & $3.36 \pm 239$ & $3.41 \pm 2.76$ & $-0.77 / .0944$ \\
\hline $\mathrm{El}$ & $82(14.8)$ & $3.75 \pm 2.47$ & $0.1-10.0$ & $4.14 \pm 2.53$ & $2.91 \pm 2.14$ & $2.132 / \mathbf{0 . 0 3 6}$ \\
\hline Sirt & 201(36.2) & $4.99 \pm 2.51$ & $0.1-10.0$ & $5.56 \pm 2.63$ & $4.11 \pm 2.05$ & $4.162 / \mathbf{0 . 0 0 0}$ \\
\hline Bel & 259(46.9) & $5.31 \pm 2.52$ & $0.1-10.0$ & $5.73 \pm 2.62$ & $4.83 \pm 2.32$ & $2.905 / \mathbf{0 . 0 0 4}$ \\
\hline Kalça & $95(17.1)$ & $4.23 \pm 2.55$ & $0.8-10.0$ & $4.49 \pm 2.67$ & $3.81 \pm 2.32$ & $1.285 / 0.202$ \\
\hline Diz & $177(31.9)$ & $4.84 \pm 2.67$ & $0.5-10.0$ & $5.04 \pm 2.77$ & $4.63 \pm 2.55$ & $1.021 / 0.309$ \\
\hline Ayak & $161(29.0)$ & $4.79 \pm 2.70$ & $0.1-10.0$ & $5.14 \pm 2.80$ & $4.27 \pm 2.48$ & $2.011 / \mathbf{0 . 0 4 6}$ \\
\hline
\end{tabular}

*Independent T test, $\mathbf{p}<0.05$

En çok ağrı şikâyeti olan 5 bölge sırasıyla bel, boyun, sirt, omuz ve diz bölgesiydi. Her iki cinsiyette de ağrı şiddeti en fazla olan bölge ise bel bölgesidir. Bu bölgenin GAS skoru ortalamas1 $5.31 \pm 2.52$ olarak saptand1. A ğr1 şiddeti an az olan vücut bölgesi ise $3.38 \pm 2.52$
GAS skoru ortalaması ile dirsek bölgesidir (Tablo 4).

KİSA olan ve olmayan öğretmenlerde vücut farkındalık, emosyonel durum ve yaşam kalitesi ölçeklerinden aldıkları puan ortalamalarının karşılaştırılması Tablo 5' te sunulmuştur. 
SSTB

www.sstbdergisi.com

International Refereed Academic Journal of Sports, Health and Medical Sciences April - May - June Issue: 27 Spring Summer Year: 2018

Uluslararası Hakemli Akademik Spor Sağlık ve Tıp Bilimleri Dergisi

Nisan - Mayıs - Haziran Sayı: 27 İlkbahar Yaz Dönemi Yıl: 2018 ID:381 K:476

ISSN Print: 2146-8508 Online 2147-1711

(ISO 18001-OH-0090-13001706 / ISO 14001-EM-0090-13001706 / ISO 9001-QM-0090-13001706 / ISO 10002-CM-0090-13001706) (TRADEMARK)

(2015/04315- 2015-GE-18972)

Tablo 5. KİSA Olan ve Olmayanlar Öğretmenlerde Vücut Farkındalık Durumu, Emosyonel Durum ve Yaşam Kalitesinin İncelenmesi

\begin{tabular}{lllll} 
& \multicolumn{2}{c}{ Ağri Durumu } & \\
\cline { 2 - 4 } & $\begin{array}{l}\text { Toplam } \\
(\mathrm{n}: 555)\end{array}$ & $\begin{array}{l}\text { Var } \\
(\mathrm{n}: 413)\end{array}$ & $\begin{array}{l}\text { Yok } \\
(\mathrm{n}: 142)\end{array}$ \\
\cline { 2 - 4 } & Ort. \pm SS & Ort. \pm SS & Ort. \pm SS & \\
\hline BDÖ & $9.57 \pm 8.49$ & $10.51 \pm 8.41$ & $6.85 \pm 8.16$ & $4.50 / \mathbf{0 . 0 0 0}$ \\
\hline VFA & $91.18 \pm 21.73$ & $91.54 \pm 21.09$ & $90.15 \pm 23.53$ & $0.656 / 0.512$ \\
\hline FRK & $63.15 \pm 38.96$ & $59.19 \pm 39.77$ & $74.64 \pm 34.07$ & $-4.135 / \mathbf{0 . 0 0 0}$ \\
\hline ERK & $63.93 \pm 40.06$ & $59.36 \pm 40.73$ & $77.23 \pm 34.92$ & $-4.668 / \mathbf{0 . 0 0 0}$ \\
\hline EBD & $58.59 \pm 18.77$ & $56.28 \pm 18.56$ & $65.30 \pm 17.81$ & $-5.048 / \mathbf{0 . 0 0 0}$ \\
\hline MS & $67.13 \pm 16.66$ & $66.03 \pm 16.52$ & $70.33 \pm 16.70$ & $-2.668 / \mathbf{0 . 0 0 8}$ \\
\hline SF & $68.88 \pm 23.45$ & $67.01 \pm 23.28$ & $74.31 \pm 23.17$ & $-3.224 / \mathbf{0 . 0 0 1}$ \\
\hline FF & $68.93 \pm 22.13$ & $65.75 \pm 21.93$ & $78.20 \pm 20.05$ & $-5.961 / \mathbf{0 . 0 0 0}$ \\
\hline A & $73.17 \pm 21.60$ & $68.64 \pm 20.89$ & $86.32 \pm 18.00$ & $-8.996 / \mathbf{0 . 0 0 0}$ \\
GSD & $59.54 \pm 17.30$ & $57.53 \pm 16.94$ & $65.39 \pm 17.09$ & $-4.758 / \mathbf{0 . 0 0 0}$
\end{tabular}

*Bağımsız gruplarda T testi, $\mathrm{p}<0.05$ VFA: Vücut Farkındalık Anketi; FRK; Fiziksel Rol Kısıtlılığ1; ERK: Emosyonel Rol Kısitlılı̆̆g; EBD: Enerji-Bitkinlik Düzeyi; MS: Mental Sağlık; SF: Sosyal Fonksiyon (SF); FF: Fiziksel Fonksiyon; A:Ağrı; GSD: Genel Sağlik Durumu.

Kat1lımcıların BDÖ skoru ortalama değeri $9.57 \pm 8.49$, VFA skoru ortalaması ise $91.18 \pm 21.73$ olarak bulundu. KİSA olan öğ- retmenlerle olmayanların BDÖ skorları karş1laştırmasında fark anlamlı (p:0.000) VFA skoru karşılaştırmasında ise fark anlamsız olarak bulundu (p:0.512) (Tablo 5).

KİSA olan öğretmenlerde vücut farkındalığ1 ile yaşam kalitesi ve emosyonel durum ölçekleri arasında korelasyon olup olmadığ 6' da gösterilmiştir. 
International Refereed Academic Journal of Sports, Health and Medical Sciences April - May - June Issue: 27 Spring Summer Year: 2018

Uluslararası Hakemli Akademik Spor Sağlık ve Tıp Bilimleri Dergisi

Nisan - Mayıs - Haziran Sayı: 27 İlkbahar Yaz Dönemi Yıl: 2018 ID:381 K:476

ISSN Print: 2146-8508 Online 2147-1711

(ISO 18001-OH-0090-13001706 / ISO 14001-EM-0090-13001706 / ISO 9001-QM-0090-13001706 / ISO 10002-CM-0090-13001706) (TRADEMARK)

Tablo 6. KİSA Olan Öğretmenlerde Vücut Farkındalık Durumu ile Emosyonel Durum ve Yaşam Kalitesi Arasındaki İlişkinin İncelenmesi

\begin{tabular}{lll} 
Ölçekler & $\mathrm{r}$ & $\mathrm{p}$ \\
\hline VFA-BDÖ & -0.108 & 0.028 \\
\hline VFA-FRK & 0.009 & 0.853 \\
\hline VFA-ERK & 0.027 & 0.581 \\
\hline VFA-EBD & 0.062 & 0.207 \\
\hline VFA-MS & 0.161 & 0.001 \\
\hline VFA-SF & 0.058 & 0.239 \\
\hline VFA-FF & 0.134 & 0.006 \\
\hline VFA-A & 0.030 & 0.545 \\
\hline VFA-GSD & 0.096 & 0.052
\end{tabular}

Pearson korelasyon analizi. VFA: Vücut Farkındalık Anketi; BDÖ; Beck Depresyon Ölçeği; FRK; Fiziksel Rol Kısıtlılığı; ERK: Emosyonel Rol Kısitlılığ1; EBD: Enerji-Bitkinlik Düzeyi; MS: Mental Sağlı; SF: Sosyal Fonksiyon (SF); FF: Fiziksel Fonksiyon; A:Ağrı; GSD: Genel Sağlık Durumu.

VFAile BDÖ skorları arasındanegatifyönlüve anlamlı bir ilişki bulundu (r:-0,108,p:0,028).
VFA skoru ile yaşam kalitesi alt değerlendirme kategorilerinden MS (r:0,161, p:0,001) ve FF (r:0,134, p:0,006) arasında pozitif yönlü ilişki bulundu (Tablo 6).

Ağrıs1 olan öğretmenlerde BDÖ ile VFA ve yaşam kalitesi SF-36 alt ölçekleri arasında korelasyon analizi tablo 7' de sunulmuştur. 
International Refereed Academic Journal of Sports, Health and Medical Sciences April - May - June Issue: 27 Spring Summer Year: 2018

Uluslararası Hakemli Akademik Spor Sağlık ve Tıp Bilimleri Dergisi

Nisan - Mayıs - Haziran Sayı: 27 İlkbahar Yaz Dönemi Yıl: 2018 ID:381 K:476

ISSN Print: 2146-8508 Online 2147-1711

(ISO 18001-OH-0090-13001706 / ISO 14001-EM-0090-13001706 / ISO 9001-QM-0090-13001706 / ISO 10002-CM-0090-13001706) (TRADEMARK)

(2015/04315- 2015-GE-18972)

Tablo 7. KİSA Olan Öğretmenlerin Emosyonel Durum ile Yaşam Kalitesi Alt Ölçekleri Arasındaki İlişkinin İncelenmesi

\begin{tabular}{lll} 
Ölçekler & $\mathrm{r}$ & $\mathrm{p}$ \\
\hline Beck Skoru -FRK & -0.313 & 0.000 \\
\hline Beck Skoru -ERK & -0.347 & 0.000 \\
\hline Beck Skoru -EBD & -0.373 & 0.000 \\
\hline Beck Skoru -MS & -0.458 & 0.000 \\
\hline Beck Skoru -SF & -0.372 & 0.000 \\
\hline Beck Skoru -FF & -0.208 & 0.000 \\
\hline Beck Skoru -A & -0.392 & 0.000 \\
\hline Beck Skoru -GSD & -0.399 & 0.000
\end{tabular}

Pearson korelasyon analizi. FRK; Fiziksel Rol Kisitlılığ1; ERK: Emosyonel Rol Kisitlılığ1; EBD: Enerji-Bitkinlik Düzeyi; MS: Mental Sağlık; SF: Sosyal Fonksiyon (SF); FF: Fiziksel Fonksiyon; A:Ağrn; GSD: Genel Sağlık Durumu.

BDÖ skoru ile yaşam kalitesi alt değerlendirme kategorilerinin tamamı arsında negatif yönlü ve anlamlı ilişki vardır. BDÖ skoru arttıkça yaşam kalitesi alt ölçek puanlarının anlamlı şekilde düştüğü görüldü (Tablo 7).

\section{TARTIŞMA}

$\mathrm{Bu}$ çalışmada öğretmenlerin ağrı durumları ile vücut farkındalığı, yaşam kalitesi ve emosyonel durumları incelenmiştir. Öğretmenlerin mesleki sağlığına odaklanan az sayıda çalışma vardır. Bu yüzden birçok ülkedeki öğretmenlerin kas iskelet sistemi rahatsızlıkları prevalansı bilinmemektedir.
Ağır kaldırma, kötü çalışma postürü, eğilme, dönme, uzun süre oturma ya da ayakta durma ve tekrarlayicı hareketleri içeren iş aktiviteleri kas iskelet sistemi rahatsızlıklarının gelişmesine katkıda bulunur. Oturarak yapılan uzun süreli kitap okuma, sınav kağıdı değerlendirme ve bilgisayar kullanımı, uzun süreli ders anlatma ve tahtada tekrarlayıcı baş üzeri yazma aktivitesi öğretmenlerde bel ve üst ekstremite ağrılarına sebep olan faktörlerdir (Malcharine et al., 2001: 79-90).

Durmuş ve İlhanlı yapmış oldukları çalışmada öğretmenlerdeki KİSA prevalansını $\% 60,3$ (Durmus\&İlhanl1, 2012: 5-12), Korkmaz ve ark. \%51.4 (Korkmaz et al., 2011: 649657), Cardosu ve ark. \%55 (Cardoso et al., 2009: 1-10), Brulin ve ark. \%40 (Brulin et al., 1998: 103-111), Allsop ve Ackland \%68 (Allsop\&Ackland, 2010; 61-78) ve Darwish ve Al-Zuhair kadın öğretmenler üzerine yap- 


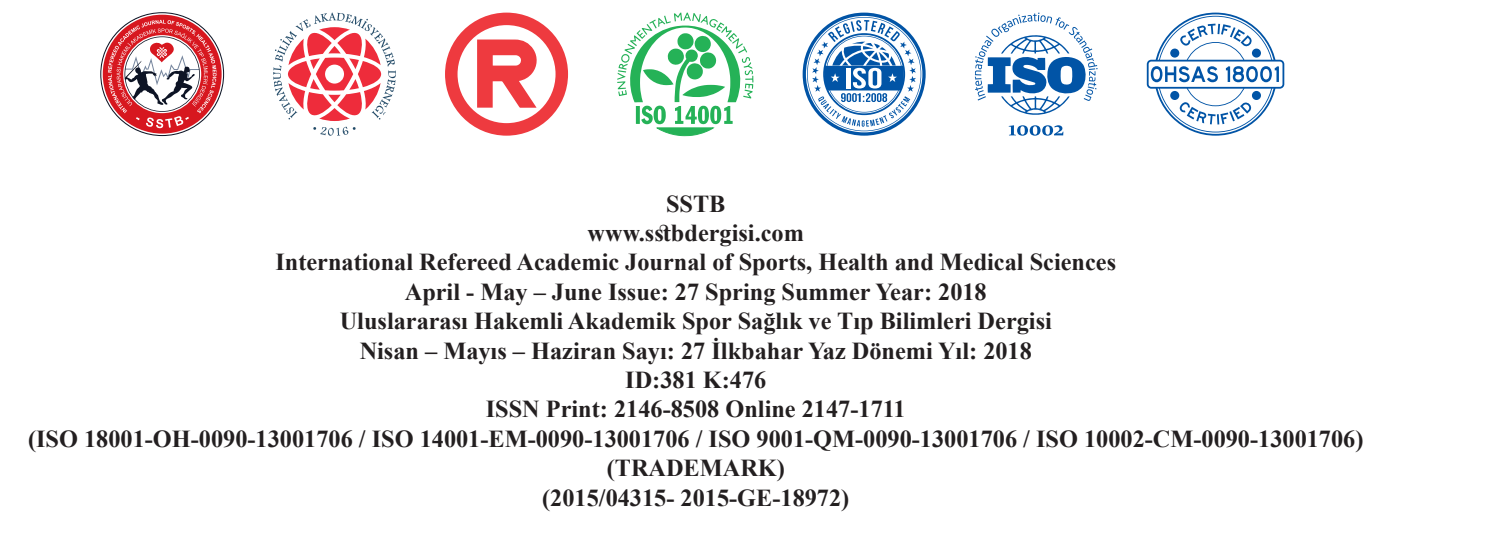

tıkları çalışmada ise \% 79.17 olarak bildirmişlerdir (Darwish \&Al-Zuhair, 2013: 1-7). Bizim çalışmamızda ise öğretmenlerdeki KİSA prevalansı Darwish ve Al-Zuhair'in yaptığ 1 çalışma ile uyumlu fakat literatür verilerinden biraz yüksek olarak (\%74.4) bulunmuştur.

Bazı çalışmalar kadın cinsiyet, ileri yaş, mesleki deneyim süresi ve çalışma süresi gibi bireysel faktörlerin öğretmenlerde KİSA gelişimi ile pozitif ilişkisi olduğunu ortaya koymuştur (Yue et al., 2012; 1-8; Korkmaz et al., 2011: 649-657; Darmawan et al., 1995: 121-124; Chiu\&Lam, 2007: 19-32). Karakaya ve ark. yaptıkları çalışmada KISA olan ve olmayan öğretmenlerde yaş, cinsiyet, mesleki deneyim süresi ve haftalık çalışma süresi arasında fark bulamamıştır (Karakaya et al., 2015: 344350). Başkurt ve ark. nın yaptıkları çalı̧̧mada KİSA varlığı ile kadın cinsiyet arasında ilişki bulmuş fakat haftalık çalışma süresi ile ilgili ilişki bulamamıştır (Baskurt et al., 2011: 5864). Durmuş ve İlhanlı KİSA olan ve olmayan öğretmenler arasında yaş ve BKİ değerlerinin benzer olduğunu (Durmus\&illhanl1, 2012: 5-12), Darwish ve Al-Zuhair'in çalışmasında yaş ile KİSA varlığı arasında anlamlı bir korelasyon olduğunu bildirmiştir (Darwish\&AlZuhair, 2013: 1-7). Bizim çalışmamızda ise kadın cinsiyet ve KİSA gelişimi arasında bir ilişki bulunmuş, yaş, BKİ, mesleki deneyim süresi, haftalık çalışma süresi gibi parametreler ile KİSA oluşumu arasında bir ilişki bulu- namamıştır. Ağrı ve cinsiyet üzerine yapılan bir çalışmada kadınların ağrıya daha fazla yatkın olduğu, hatta KİSA prevalansının erkeklerden daha fazla olduğu bildirilmiş ve ağrının nedenleri olarak cinsiyet fark1, genetik, psikolojik, anatomik, nöral, hormonal farkliliklar, yaşam tarzı ve kültürel farklardan oluştuğu bildirilmiştir (Şahin, 2004: 1-9).

En sık ağrı görülen vücut bölgeleri Korkmaz ve ark. yaptığ çalışma sonucuna göre bel (\%43.8) ve boyun (\%42.5) (Korkmaz et al., 2011: 649-657), Karakaya ve ark. yaptığı çalışmada boyun (\%39), Bel (\%38) (Karakaya et al., 2015: 344-350), Durmuş ve İlhanlının yaptığı çalışmada bel (\%74.9), omuz (\%55.9) ve boyun (47,9) ( Durmus \&İlhanl1, 2012: 5-12) olarak bildirilmiştir. Chiu ve Lam boyun bölgesinin ağrn prevalansını \% 69.3 (Chiu\&Lam, 2007: 19-32), Yue ve Ark. ise bel bölgesi ağrı prevalansını \%48.7 olarak bildirmiştir (Yue et al., 2012: 1-8). Bizim yaptığımız çalışma sonucuna göre en fazla ağrryan vücut bölgeleri literatüre uyumlu olarak bel (\%46.9) ve boyun (39.6) olarak bulunmuştur. Cinsiyetler arasında karşılaş̧ırma yapıldığında erkelerde en fazla ağriyan bölge bel (\%46.3), kadınlarda ise boyun (\%64.1) bölgesidir. Öğretmenlerin uzun süre ayakta durarak çalışmaları, masa başı yaptıkları çalışmalarda ise başın uzun süreli fleksiyon pozisyonu gibi nedenlerle bel ve boyun bölgelerinde daha fazla ağrı görülmesi beklenen bir durumdur. 
International Refereed Academic Journal of Sports, Health and Medical Sciences April - May - June Issue: 27 Spring Summer Year: 2018

Uluslararası Hakemli Akademik Spor Sağlık ve Tıp Bilimleri Dergisi

Nisan - Mayıs - Haziran Sayı: 27 İlkbahar Yaz Dönemi Yıl: 2018 ID:381 K:476

ISSN Print: 2146-8508 Online 2147-1711

(ISO 18001-OH-0090-13001706 / ISO 14001-EM-0090-13001706 / ISO 9001-QM-0090-13001706 / ISO 10002-CM-0090-13001706) (TRADEMARK)

(2015/04315- 2015-GE-18972)

KİSA olan öğretmenlerde yaşam kalitesini araştıran az sayıda çalışma yapılmıştır. Durmuş ve İlhanlı yapmış oldukları çalışmada KİSA olan öğretmenlerin SF-36 alt ölçeklerinden duygusal rol kısıtlaması, ruh sağlı̆̆1 ve enerji alt ölçekleri dışında kalan tüm ölçek skorları ağrısı olmayanlara göre düşük bulunmuştur (Durmus\&İlhanl1, 2012: 5-12). Karakaya ve ark. yapmış olduğu çalışmada ise ağrı ve enerji alt ölçekleri KİSA olanlarda daha düşük olarak bulunmuştur (Karakaya et al., 2015: 344-350). Bizim çalışmamızda ise KİSA olan öğretmenlerde SF-36'nın tüm alt ölçekleri anlamlı şekilde daha düşük olarak bulunmuştur. $\mathrm{Bu}$ sonuçlar KİSA varlığının yaşam kalitesi üzerine olumsuz etkisi oldugunu ortaya koymaktadır.

Kronik ağrı varlığg depresyon ya da diğer psikolojik durumlar ile sık sık ilişkilendirilmiştir (Kerssens et al., 2002: 203-212). Vogt ve ark. ağrı şiddeti arttığında depresif semptomlarında arttığını bildirmiştir (Vogt et al., 2003: 435-441). Durmuş ve İlhanlı yaptıkları çalışmada KİSA olan öğretmenlerde depresif semptomların daha fazla (BDÖ puan ortalaması $=7.0$ ) olduğunu bildirmişlerdir (Durmus\&İlhanl1, 2012: 5-12). Bizim çalışmamızın sonuçları da literatürle uyumlu bir şekilde KİSA olanlarda BDÖ puan ortalaması ağrıs1 olmayanlara göre daha yüksek olduğu görülmüştür. Ağrı ile ilişkili olarak psikolojinin nedensel bir faktör olduğu bazı çalışma- larda belirtilmiştir ancak ağrı sonrası psikolojik bozuklukların mı arttığı yoksa psikolojik bozukluklara eşlik eden bir ağrı varlığının olduğuna dair çalışmalar yetersizdir (Şahin, 2004: 1-9; Korkmaz et al., 2011: 649-657).

VFA normal ve duyusal olmayan vücut süreçlerinin ve farkındalıklarının ortaya konulabilmesi için güvenilir bir araçtır (Shield et al., 1989: 802-815). Bu çalışmanın sonucunda KİSA olan öğretmenler ile olmayanlar arasında vücut farkındalık durumu puan ortalamaları arasındaki fark anlamlı bulunamadı. Vücut farkındalık durumu ile yaşam kalitesi değerlendirmesi alt skorlarından sadece mental sağlık düzeyi arasında pozitif yönlü ilişki bulundu. Mental sağlık düzeyi arttıkça vücut farkındalık durumunda da artış olduğu görülmüştür ( $p=0.001)$. Ayrıca vücut farkındalık durumu ile emosyonel durum arasinda negatif yönlü bir ilişki bulunmuştur.(r:-0.108, $\mathrm{p}: 0,028)$

\section{SONUÇ}

Sonuç olarak bu çalışmada öğretmenlerde KİSA prevalansın yüksek olarak bulunmuş, yaşam kalitesi ve emosyonel durum üzerine olumsuz etkileri olduğu ortaya konmuştur. Öğretmenlerde en çok ağrıyan bölge sırt ve boyun bölgesi, ağr1 şiddeti en fazla olan bölge ise bel bölgesi olarak karşımıza çıkmaktadır. Çalışmamızda öğretmenlerde KİSA oluşumuna sebep olabilecek en önemli faktö- 


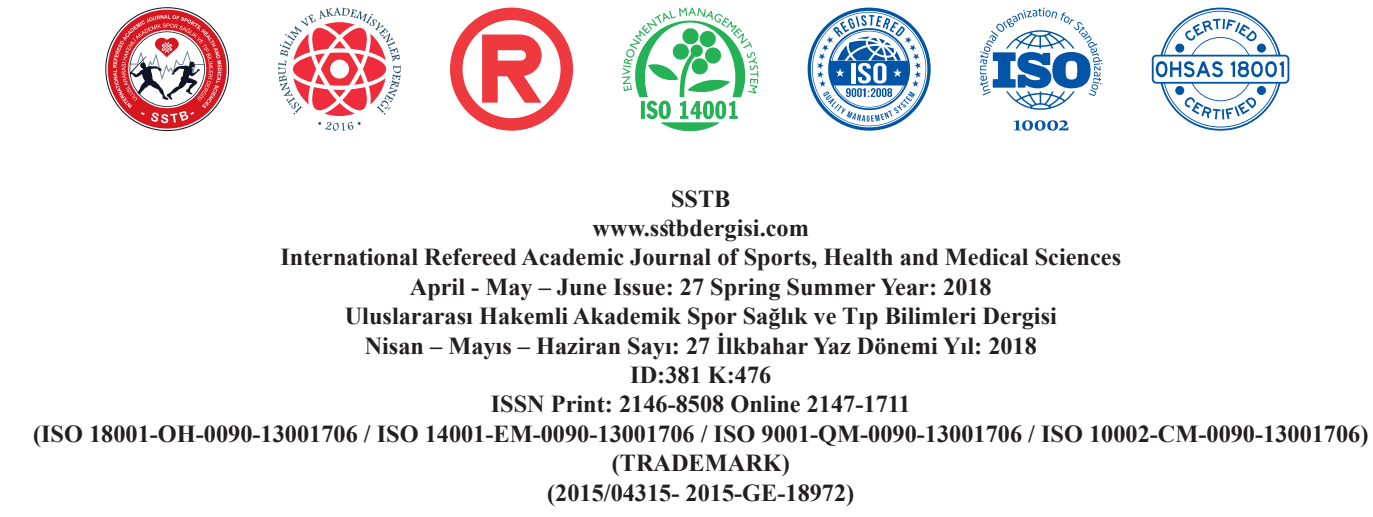

rün cinsiyet farklılığı olduğu sonucuna ulaşı1mıştır. Bunun nedeninin kadın öğretmenlerin öğretmenlik mesleği dışında ev işleri ile de uğraşmaları olabileceği düşünülmektedir.

Öğretmenlerde KİSA varlığı sadece öğretmenlerin sağlik durumunu etkileyen bir problem değil, aynı zamanda eğitim ve öğretim işini etkileyen önemli bir faktördür. $\mathrm{Bu}$ nedenle öğretmenlerde KİSA' na sebep olabilecek faktörleri tanımlamak ve bunları önlemeye yönelik çalışmalar yapmak hem öğretmenlerin yaşam kalitesini arttıracak hem de eğitim ve öğretim işinin daha sağlıklı yapılmasına katkı sağlayacağı düşünülmektedir.

\section{REFERANSLAR}

ALLSOP, L., ACKLAND, T., (2010). The prevalence of playing-related musculoskeletal disorders in relation to piano players' playing techniques and practising strategies. Music Performance Research, 3(1):61-78

ATLAS, A.P., BONDOC, R.G., GARROVILLAS, R.A., LO, R.D., RECINTO, J., YU, K.J., (2007). Prevalence of low back pain among public high school teachers in the city of manila. philippine Journal of Allied Health Sciences, 2(1):34-40

\section{BASKURT, F., BASKURT, Z., GELECEK,}

N., (2011). Prevalence of selfreported musculoskeletal symptoms in teachers.
SDU Sağlık Bilimleri Enstitüsü Dergisi, 2(2):58-64

BRULIN, C., GOINE, H., EDLUND, C., KNUTSSON, A., (1998). Prevalence of long-term sick leave among female home care personnel in northern Sweden. Journal of Occupational Rehabilitation, $8(2): 103-111$

CORREA, L.A., SANTOS, L.T., PARANHOS, E.N.N., ALBERTINI, A.I.M., PARREIRA, P.C.S., NOGUEIRA, L.A.C., (2018). Prevalence and risk factors for musculoskeletal pain in keyboard musicians: a systematic review. Analytical Review, 1-9. https://doi.org/10.1016/j. pmrj.2018.04.001

CARDOSO, J.P., ET AL., (2009). Prevalence of musculoskeletal pain among teachers. Brazilian Journal of Epidemiology, 12:1-10

CHIU, T.T., LAM, P.K., (2007). The prevalence of and risk factors for neck pain and upper limb pain among secondary school teachers in Hong Kong. J Occupational Rehabilitation, 17(1): 19-32

CHONG, E.Y.L., CHAN, A.H.S., (2010). Subjective health complaints of teachers fromprimary and secondary schools in Hong Kong, International Journal 
International Refereed Academic Journal of Sports, Health and Medical Sciences April - May - June Issue: 27 Spring Summer Year: 2018 Uluslararası Hakemli Akademik Spor Sağlık ve Tıp Bilimleri Dergisi Nisan - Mayıs - Haziran Sayı: 27 İlkbahar Yaz Dönemi Yıl: 2018 ID:381 K:476

ISSN Print: 2146-8508 Online 2147-1711

(ISO 18001-OH-0090-13001706 / ISO 14001-EM-0090-13001706 / ISO 9001-QM-0090-13001706 / ISO 10002-CM-0090-13001706) (TRADEMARK)

of Occupational Safety and Ergonomics, 16(1): 23-39

DARMAWAN, J., VALKENBURG, H.A., MUIRDEN, K.D., WIGLEY, R.D. (1995). The prevalence of soft tissue rheumatism. A who-ilar copcord study. Rheumatology International, 15(3): 121-124

DARWISH, M.A., AL-ZUHAIR, S.Z., (2013). Musculoskeletal pain disorders among secondary school Saudi female teachers. Pain Research and Treatment, 878570, 1-7. doi. org/10.1155/2013/878570

DURMUS, D., ILHANLI, I., (2012). Are there work-related musculoskeletal problems among teachers in Samsun, Turkey? Journal of Back\&Musculoskelet Rehabilitation, 25(1): 5-12

ERDEN, A., ALTUĞ, F., CAVLAK, U., (2013). Sağlıklı kişilerde vücut farkındalık durumu ile ağrı, emosyonel durum ve yaşam kalitesi arasındaki ilişkinin incelenmesi. Journal of Kartal Training and Research Hospital, 24(3): 145-150 doi: 10.5505/jkartaltr.2013.20438

GASPARINI, S.M., BARRETO, S.M., ASSUNÇÃO, A.A., (2005). O professor, as condições de trabalho e os efeitos sobre sua saúde. Educação e Pesquisa, 31(2): 189-199
HISLI, N., (1998). Beck Depresyon ölçeğinin bir Türk örnekleminde geçerlilik ve güvenirliliği, Psikoloji Dergisi, (6): $118-122$

KARAKAYA, I.Ç., KARAKAYA, M.G., TUNÇ, E., KIHTIR, M., (2015). Musculoskeletal problems and quality of life of elementary school teachers, International Journal of Occupational Safety and Ergonomics, 21(3) :344-350. doi: $10.1080 / 10803548.2015 .1035921$

KERSSENS, J.J., VERHAAK, P.F.M, BARTELDS, A.I.M., SORBI, M.J., BENSING, J.M., (2002). Unexplained severe chronic pain in general practice. Eur. Journal of Pain, (6): 203-212

KORKMAZ, N. C., CAVLAK, U., TELCI, E. A., (2011). Musculoskeletal pain, associated risk factors and coping strategies in school teachers, Scientific Research and Essays, 6(3): 649-657

LEE, N., SUNG, H., KIM, J.H., PUNNET, L., KIMM, S.S., (2017). Perceived discrimination and low back pain among 28,532 workers in South Korea: Effect modification by labor union status. Social Science\& Medicine, (177): 198-204

MALCHAIRE, J., COCK, N., VERGRACHT, S., (2001). Review of the factors associated with musculoskeletal 
SSTB

www.sstbdergisi.com

International Refereed Academic Journal of Sports, Health and Medical Sciences April - May - June Issue: 27 Spring Summer Year: 2018

Uluslararası Hakemli Akademik Spor Sağlık ve Tıp Bilimleri Dergisi

Nisan - Mayıs - Haziran Sayı: 27 İlkbahar Yaz Dönemi Yıl: 2018 ID:381 K:476

ISSN Print: 2146-8508 Online 2147-1711

(ISO 18001-OH-0090-13001706 / ISO 14001-EM-0090-13001706 / ISO 9001-QM-0090-13001706 / ISO 10002-CM-0090-13001706) (TRADEMARK)

problems in epidemiological studies. Int Archives of Occupational Environmental Health, 74(2): 79-90

MUNOZ, L.C., ET AL., (2004). Comparison of three rating scales for measuring subjective phenomena in clinical research. I. Use of experimentally controlled auditory stimuli. Archives of Medical Research, (35): 43-48

PINAR, R., (2005). Reliability and construct validity of the SF-36 in Turkish cancer patients. Quality of Life Research, (14): 259-264

REIS, E.J.F.B, ET AL., (2006). Docência e exaustão emocional. Educação \& Sociedade, 27(94): 229-53

SAMAD, N.I.A., ET AL., (2010). Prevalence of low back pain and its risk factors among school teachers. American Journal of Applied Sciences, 7(5): 634-639

SHIELDS, S.A., ET AL., (1989). The body awareness questionnaire: reliability and validity. Journal of Personality Assessment, (53): 802-815
SMEDLEY, J., ET AL., (1955). Manuel handling activities and risk of low back pain in nurses. Occupational and Environmental Medicine, (52): 160-163

ŞAHIN, Ş., (2004). Ağr1 ve cinsiyet. Ağr1, 16(2): $17-25$

TÜRKIYYE CUMHURIYYETI SĂ̈LIK BAKANLIĞI. (2014). Türkiye Fiziksel Aktivite Rehberi, Ankara, Türkiye. Anıl Matbaa, Sağlık Bakanlığı yayın no:940: $1-120$

VOGT, M.T., ET AL., (2003). Neck and shoulder pain in 70- to 79-year- old men and women: findings from the health, aging and body composition study. The Spine Journal, (3): 435-441

WATERFIELD, J., SIM, J., (1996). Clinical assessment of pain by visual analogue scale. British Journal of Therapy and Rehabilitation, (3): 94-7

YUE, P., ET AL., (2012). Neck/shoulder pain and low back pain among school teachers in China, prevalence and risk factors. BMC Public Health, (12): 789 


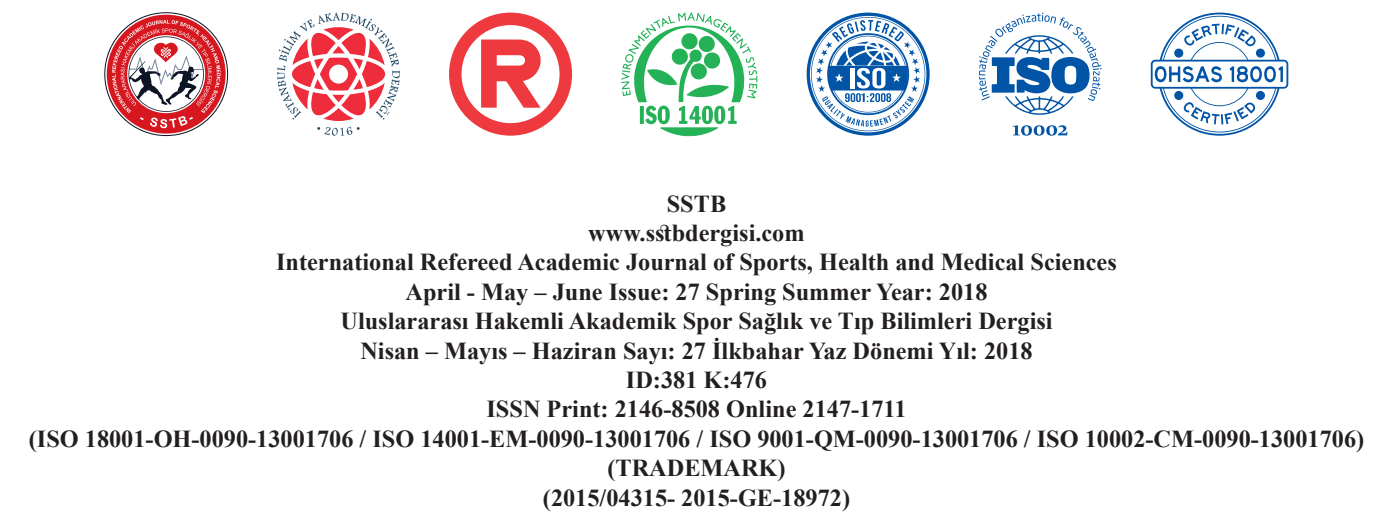

\section{EXTENDED ABSTRACT}

Introduction: Musculoskeletal pain is one of the most common health problems in the working population, which is an economically significant burden that has a significant impact on quality of life. (Samad et al., 2010: 634-639; Correa et al., 2018: 1-9). Musculoskeletal disorders include inflammatory and degenerative conditions affecting muscles, ligaments, tendons, nerves bones and joints (Allsop\&Ackland, 2010: 61-78; Atlas et al.,2007:34-40). Factors contributing to this situation are workplace activities such as exhaustive and repetitive activities and intense workload (Smendley et al., 1995: 160-163). It is known that demographic characteristics such as age, sex, smoking habits are variables that can cause this situation (Lee et al, 2017: 198-204). Some occupational group employees are more exposed to musculoskeletal disorders due to occupational characteristics (Gasparini et al., 2005: 99-189). Teachers take part in this group. Sometimes teaching takes place under unfavorable conditions in which teachers make more efforts to reach their teaching, physical, cognitive and emotional capacities (Cardoso et al., 2009: 1-10). If there is not enough time for recovery, the increase in level of job-related leave resulting from health status of employees will result in an increase in the level of physical health, mental health and performance, which makes the training job more difficult (Gasparini et al.,2005:99-189; Reis et al.,2006:53-229). Many international studies have been reported on the prevalence of musculoskeletal pain in teachers (Chang and Chan, 2010: 23-29; Darmawan et al., 1995: 121-124). In general, musculoskeletal system disorders in teachers are much higher than other occupational groups (Cardoso et al.,2009:1-10). It was reported as in a study that prevalence of musculoskeletal disorders conducted in Saudi Arabia 79,17\% (Darwish\&A1-Zuhair, 2013: 1-7), a study in Brasil 55\% (Cardoso et al.,2009:1-10), in different studies conducted in our country 59.4\% (Durmus\&İlhanl1, 2012: 5-12) and 77\% (Karakaya et al., 2015: 344-350) Aim: The aim of this study is to determine the prevalence of musculoskeletal system pain, the effects of pain on emotional status, quality of life and body awareness in the intended teachers. Materials and Methods: This cross-sectional study included 555 teachers working in public schools. The SF-36 quality of life questionnaire was used to assess the quality of life of the teachers, the Beck Depression Scale to assess the emotional state, the body awareness questionnaire to assess body awareness and the visual analogue scale to measure pain severity. The Statistical Package for Social Sciences (SPSS) software Version 22.0 was used for statistical analysis. Chi-square hypothesis test was used to test for associations between the each scale and the socio-demographic characteristics of teachers. Significance 
International Refereed Academic Journal of Sports, Health and Medical Sciences April - May - June Issue: 27 Spring Summer Year: 2018

Uluslararası Hakemli Akademik Spor Sağlık ve Tıp Bilimleri Dergisi

Nisan - Mayıs - Haziran Sayı: 27 İlkbahar Yaz Dönemi Yıl: 2018 ID:381 K:476

ISSN Print: 2146-8508 Online 2147-1711

(ISO 18001-OH-0090-13001706 / ISO 14001-EM-0090-13001706 / ISO 9001-QM-0090-13001706 / ISO 10002-CM-0090-13001706) (TRADEMARK)

(2015/04315- 2015-GE-18972)

levels were set at the 5\% level using the hypothesis tests. Correlation analysis was performed to evaluate the independent association existing between the potential risk factors and Quality of Life-36, Beck Depression Inventory, Body Awareness Questionnaire. The results were presented in odds ratios and $95 \%$ confidence intervals. The study protocol had been approved by the Ethical Committee of Kahramanmaras Sutcu Imam University (Ref. No: 2017/01), and verbal consent was obtained from the teachers before the interview. Results: $280(n=555)$ teachers were female and 275 were male. 413 teachers reported that they had pain in the musculoskeletal system. The most common areas were waist (46.9\%), neck (39.6\%), back (36.2\%) and shoulder $(32.5 \%)$. Teachers with pain in the musculoskeletal system had a high Beck Depression Inventory score and a low score of SF-36. There was no difference between body Awareness questionnaire scores of teachers with and without pain in the musculoskeletal system. There was a negative and significant correlation between Body Awareness Questionnaire and Beck Depression Inventory scores (r: -0,108, p: 0,028). There was a positive correlation between the Body Awareness Questionnaire score and the quality of life subscales; Mental Health (MH) (r: 0,161, p: 0,001) and Physical Function (PF) (r: 0,134, p: 0,006). Conclusion: The prevalence of pain in the musculoskeletal system was high in the teachers and accordingly, the teachers who had the pain in the musculoskeletal system had a decrease in quality of life and a predisposition to depression. 